\title{
Molecular Basis of Inhibitory Activities of Berberine against Pathogenic Enzymes in Alzheimer's Disease
}

\author{
Hong-Fang Ji and Liang Shen \\ Shandong Provincial Research Center for Bioinformatic Engineering and Technique, Shandong University of Technology, \\ Zibo 255049, China \\ Correspondence should be addressed to Liang Shen, shen@sdut.edu.cn
}

Received 27 October 2011; Accepted 16 November 2011

Academic Editor: Robert Perneczky

Copyright ( $\odot 2012$ H.-F. Ji and L. Shen. This is an open access article distributed under the Creative Commons Attribution License, which permits unrestricted use, distribution, and reproduction in any medium, provided the original work is properly cited.

The natural isoquinoline alkaloid berberine possesses potential to treat Alzheimer's disease (AD) by targeting multiple pathogenic factors. In the present study, docking simulations were performed to gain deeper insights into the molecular basis of berberine's inhibitory effects against the important pathogenic enzymes of $\mathrm{AD}$, that is, acetylcholinesterase, butyrylcholinesterase, and two isoforms of monoamine oxidase. It was found that the theoretical binding affinities of berberine to the four enzymes are very close to the experimental values, which verify the methodology. Further inspection to the binding modes found that hydrophobic interactions between the hydrophobic surface of berberine and neighboring hydrophobic residues are the principal forces contributing to the ligand-receptor interactions. Although berberine cation also has potential to form electrostatic interaction with neighboring residues, it is interesting to find that electrostatic force is excluded in the four cases unexpectedly. These results have important implications for the berberine-based anti-AD drug design.

\section{Introduction}

As a natural isoquinoline alkaloid isolated from the Chinese herb Rhizoma coptidis, berberine (Figure 1) has gained considerable attention because of its wide spectrum of biochemical and pharmacological potentials, including antioxidant, antiinflammatory, anticancer activities, and so forth, [16]. Alzheimer's disease (AD) is the most common form of degenerative dementia with an estimated prevalence of 30 million people worldwide, and with the accelerated aging of human society, its prevalence is expected to rise steadily [7-10]. In recent years, multiple lines of evidence support that berberine also possesses potential to act as a multipotent agent to treat $\mathrm{AD}$ [11-14]. For instance, many experimental studies reported that berberine exhibits inhibitory effects against several key enzymes implicated in the pathogenesis of $\mathrm{AD}$, including acetylcholinesterase (AChE), butyrylcholinesterase (BChE), and monoamine oxidase (MAO) [14-22]. With the aim to elucidate the molecular basis of berberine's inhibitory effects against the pathogenic enzymes in $\mathrm{AD}$, in the present study, the binding modes of berberine with four enzymes, that is, AChE,
BChE, MAO-A, and MAO-B, were investigated by means of docking simulations. The results indicate that hydrophobic interactions are the principal forces contributing to the binding of berberine to the four enzymes. Despite the cation ion in berberine structure (Figure 1) can interact readily with the negatively charged acidic residues, no electrostatic force is observed unexpectedly in the four cases. The findings have important implications for the berberine-based antiAD drug design.

\section{Methods}

2.1. Structural Models. Structure coordinates for AChE, BChE, MAO-A, and MAO-B were taken from the Protein Data Bank (PDB codes: 1EA5 [23], 1P0I [24], 1O5 W [25], and 1 GOS [26], resp.). The 3D structure of berberine was firstly constructed using standard geometric parameters of SYBYL software and then was optimized using Powell method with the Tripos force field (distance-dependent dielectric) to reach a final energy convergence gradient value of $0.001 \mathrm{kcal} / \mathrm{mol}$. 


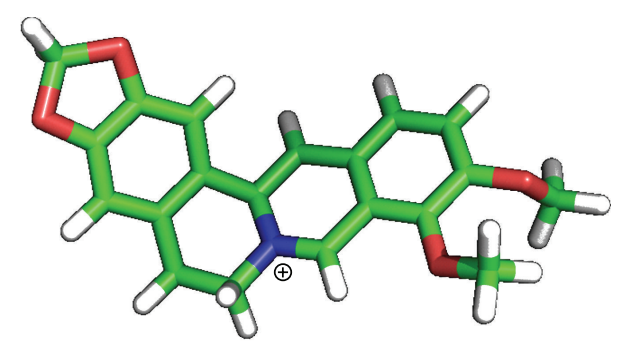

Figure 1: Chemical structure of berberine.

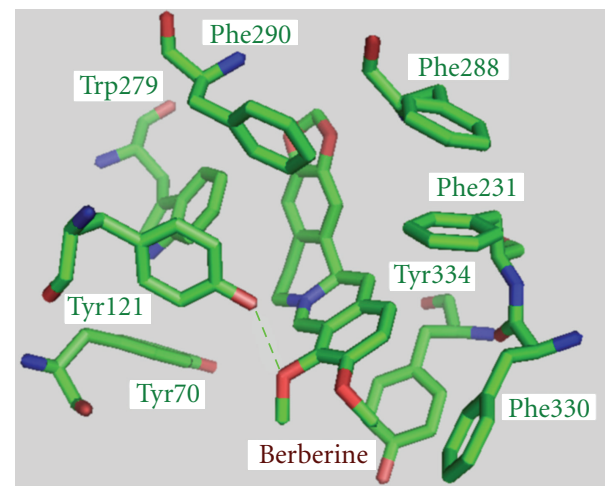

(a)

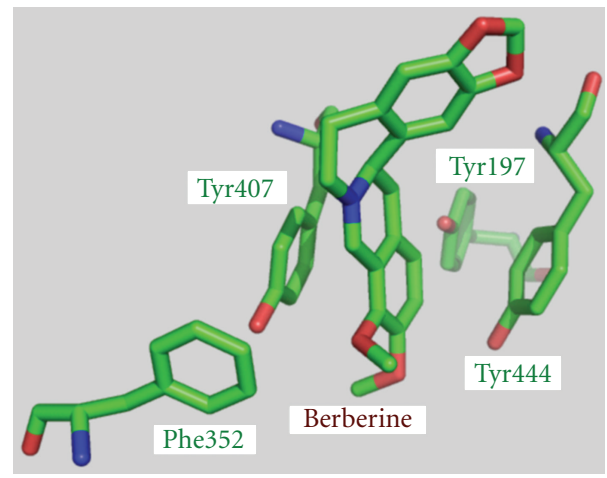

(c)

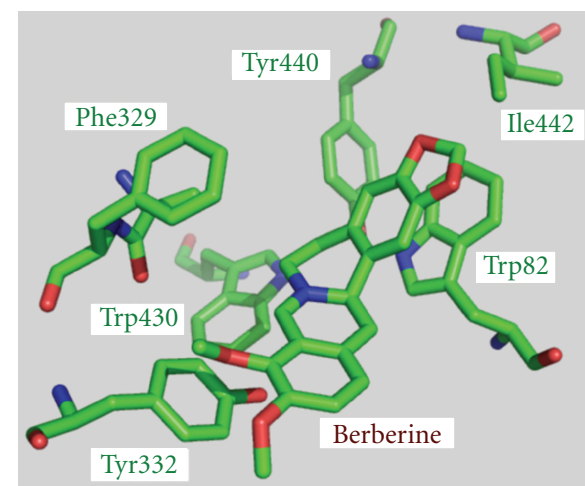

(b)

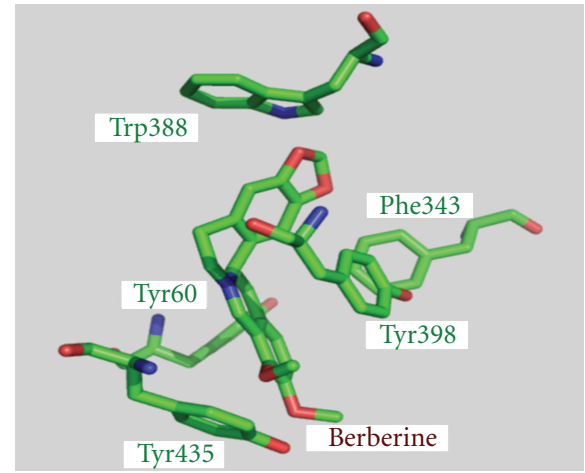

(d)

Figure 2: Close-up views of binding modes of berberine in AChE (a), BChE (b), MAO-A (c), and MAO-B (d). The hydrogen bond is marked in green dotted lines.

2.2. Docking Methods. The Surflex-Dock program interfaced with SYBYL software is employed to perform docking experiments in this study, which uses an empirically derived scoring function based on the binding affinities of proteinligand complexes and on their X-ray structures [27]. As a flexible docking method, Surflex-Dock has been proven to be efficient in treating numerous protein receptors $[27,28]$. The active sites for four targets were selected on the basis of experimentally reported key residues, which play key roles in their catalytic activities [23-26]. During the simulations, the Kollman-all atom charges were assigned to protein atoms using SYBYL software. For berberine molecule, 30 conformations were selected to dock with target in each run. Standard parameters were used to estimate the binding affinity characterized by Surflex-Dock scores. Surflex-Dock scores (total scores) are expressed in $-\log 10\left(K_{d}\right)$ units to represent binding affinities [29, 30].

\section{Results and Discussion}

The theoretical binding constants of berberine to AChE, BChE, MAO-A, and MAO-B are estimated and listed in Table 1. It can be seen that berberine possesses inhibitory activity against the four enzymes and the respective binding affinities vary largely. The theoretical $K_{d}$ of berberine to AChE $(0.66 \mu \mathrm{M})$, BChE $(3.31 \mu \mathrm{M})$, MAO-A (105.2 $\mu \mathrm{M})$, and MAO-B $(66.0 \mu \mathrm{M})$ are very close to the experimental values (Table 1), which verify the accuracy of the present methodology. According to the theoretical $K_{d}$, the inhibitory activity of berberine against AChE is the highest among the 
TABLE 1: Theoretically estimated binding constants $\left(K_{d}\right)$ of berberine with $\mathrm{AChE}, \mathrm{BChE}, \mathrm{MAO}-\mathrm{A}$, and $\mathrm{MAO}-\mathrm{B}$, and experimental $\mathrm{IC}_{50}$.

\begin{tabular}{lcl}
\hline Targets & Theoretical $K_{d}(\mu \mathrm{M})$ & Experimental $\mathrm{IC}_{50}(\mu \mathrm{M})$ \\
\hline AChE & 0.66 & $0.44[14], 0.58[15], 0.37[16]$ \\
BChE & 3.31 & $3.44[14]$ \\
MAO-A & 105.2 & $126[19]$ \\
MAO-B & 66.0 & $98.2[20], 98.4[21]$ \\
\hline
\end{tabular}

four enzymes, which is in agreement with the experimental results.

To elucidate the forces contributing to the binding affinity, the binding modes of berberine in AChE, BChE, MAO$\mathrm{A}$, and MAO-B are shown in Figure 2. From the molecular structure point of view, berberine has a large hydrophobic surface and a cation ion, which is ideal for interacting with the hydrophobic residues and the negatively charged acidic residues (Figure 1). As shown in Figure 2, the neighboring residues to berberine in the four enzymes are almost all aromatic and/or hydrophobic amino acids. Therefore, these residues can readily form hydrophobic interactions with the hydrophobic surface of berberine. According to Figure 2, there are eight hydrophobic residues (four phenylalanine, three tyrosine, and one tryptophan) interacting with berberine in AChE, while only six hydrophobic residues (one phenylalanine, two tyrosine, two tryptophan, and one isoleucine) with respect to the binding pocket in BChE. Also, a hydrogen bond is formed between berberine and Tyr121 in AChE (Figure 2), which will strengthen the binding affinity and enhance the inhibitory activity of berberine against AChE. These two aspects may account for the relatively stronger binding of berberine to AChE than BChE. In addition, there are less hydrophobic residues involved in the binding of berberine to MAO-A and MAO-B (Figure 2), which results in their much lower binding affinity.

Although berberine cation also has the potential to form electrostatic interaction with neighboring residues in four enzymes, it is interesting to find that as no corresponding negatively charged acidic residues exist at proper positions, no electrostatic interaction is observed. Therefore, according to the present results, the inhibitory activities of berberine against four targets mainly arise from hydrophobic interactions.

\section{Conclusions}

In conclusion, the theoretically estimated binding affinities of berberine to the four enzymes, $\mathrm{AChE}, \mathrm{BChE}, \mathrm{MAO}-\mathrm{A}$, and MAO-B, are very close to the experimental values. According to the binding modes, the hydrophobic interactions between berberine and surrounding hydrophobic residues in the enzymes play predominant roles, while electrostatic force is excluded in the binding of berberine to the four targets. These findings shed lights on the molecular basis of the inhibitory effects of berberine against the enzymes implicated in the pathogenesis of $\mathrm{AD}$ and will be helpful for the berberine-based anti-AD drug design.

\section{Acknowledgment}

This work was supported by the National Natural Science Foundation of China (Grant no. 30800184).

\section{References}

[1] M. Imanshahidi and H. Hosseinzadeh, "Pharmacological and therapeutic effects of Berberis vulgaris and its active constituent, berberine," Phytotherapy Research, vol. 22, no. 8, pp. 999-1012, 2008.

[2] P. R. Vuddanda, S. Chakraborty, and S. Singh, "Berberine: a potential phytochemical with multispectrum therapeutic activities," Expert Opinion on Investigational Drugs, vol. 19, no. 10, pp. 1297-1307, 2010.

[3] C. L. Kuo, C. W. Chi, and T. Y. Liu, "The anti-inflammatory potential of berberine in vitro and in vivo," Cancer Letters, vol. 203, no. 2, pp. 127-137, 2004.

[4] Y. Sun, K. Xun, Y. Wang, and X. Chen, "A systematic review of the anticancer properties of berberine, a natural product from Chinese herbs," Anti-Cancer Drugs, vol. 20, no. 9, pp. 757-769, 2009.

[5] L. Račková, M. Májeková, D. Košt’álová, and M. Štefek, "Antiradical and antioxidant activities of alkaloids isolated from Mahonia aquifolium. Structural aspects," Bioorganic \& Medicinal Chemistry, vol. 12, no. 17, pp. 4709-4715, 2004.

[6] F. R. Stermitz, P. Lorenz, J. N. Tawara, L. A. Zenewicz, and K. Lewis, "Synergy in a medicinal plant: antimicrobial action of berberine potentiated by 5-methoxyhydnocarpin, a multidrug pump inhibitor," Proceedings of the National Academy of Sciences of the United States of America, vol. 97, no. 4, pp. 14331437, 2000.

[7] C. Ballard, S. Gauthier, A. Corbett, C. Brayne, D. Aarsland, and E. Jones, "Alzheimer's disease," The Lancet, vol. 377, no. 9770, pp. 1019-1031, 2011.

[8] D. M. Holtzman, J. C. Morris, and A. M. Goate, "Alzheimer's disease: the challenge of the second century," Science Translational Medicine, vol. 3, no. 77, p. 77sr1, 2011.

[9] J. L. Cummings, "Alzheimer's disease," The New England Journal of Medicine, vol. 351, no. 1, pp. 56-57, 2004.

[10] B. L. Plassman, K. M. Langa, G. G. Fisher et al., "Prevalence of dementia in the United States: the aging, demographics, and memory study," Neuroepidemiology, vol. 29, no. 1-2, pp. 125$132,2007$.

[11] F. Zhu and C. Qian, "Berberine chloride can ameliorate the spatial memory impairment and increase the expression of interleukin-1 beta and inducible nitric oxide synthase in the rat model of Alzheimer's disease," BMC Neuroscience, vol. 7, article 78, 2006.

[12] H-F. Ji and L. Shen, "Berberine: a potential multipotent natural product to combat Alzheimer's disease," Molecules, vol. 16, no. 8, pp. 6732-6740, 2011.

[13] M. Ye, S. Fu, R. Pi, and F. He, "Neuropharmacological and pharmacokinetic properties of berberine: a review of recent research," Journal of Pharmacy and Pharmacology, vol. 61, no. 7, pp. 831-837, 2009.

[14] H. A. Jung, B. S. Min, T. Yokozawa, J. H. Lee, Y. S. Kim, and J. S. Choi, "Anti-Alzheimer and antioxidant activities of coptidis rhizoma alkaloids," Biological \& Pharmaceutical Bulletin, vol. 32, no. 8, pp. 1433-1438, 2009. 
[15] K. Ingkaninan, P. Phengpa, S. Yuenyongsawad, and N. Khorana, "Acetylcholinesterase inhibitors from Stephania venosa tuber," Journal of Pharmacy and Pharmacology, vol. 58, no. 5, pp. 695-700, 2006.

[16] L. Huang, Z. Luo, F. He, A. Shi, F. Qin, and X. Li, "Berberine derivatives, with substituted amino groups linked at the 9-position, as inhibitors of acetylcholinesterase/butyrylcholinesterase," Bioorganic \& Medicinal Chemistry Letters, vol. 20, no. 22, pp. 6649-6652, 2010.

[17] L. Huang, A. Shi, F. He, and X. Li, "Synthesis, biological evaluation, and molecular modeling of berberine derivatives as potent acetylcholinesterase inhibitors," Bioorganic \& Medicinal Chemistry, vol. 18, no. 3, pp. 1244-1251, 2010.

[18] D. K. Kim, K. T. Lee, N. I. Baek et al., "Acetylcholinesterase inhibitors from the aerial parts of Corydalis speciosa," Archives of Pharmacal Research, vol. 27, no. 11, pp. 1127-1131, 2004.

[19] L. D. Kong, C. H. K. Cheng, and R. X. Tan, "Monoamine oxidase inhibitors from rhizoma of Coptis chinensis," Planta Medica, vol. 67, no. 1, pp. 74-76, 2001.

[20] S. S. Lee, M. Kai, and M. K Lee, "Effects of natural isoquinoline alkaloids on monoamine oxidase activity in mouse brain: inhibition by berberine and palmatine," Medical Science Research, vol. 27, no. 11, pp. 749-751, 1999.

[21] J. Castillo, J. Hung, M. Rodriguez, E. Bastidas, I. Laboren, and A. Jaimes, "LED fluorescence spectroscopy for direct determination of monoamine oxidase B inactivation," Analytical Biochemistry, vol. 343, no. 2, pp. 293-298, 2005.

[22] S. K. Kulkarni and A. Dhir, "On the mechanism of antidepressant-like action of berberine chloride," European Journal of Pharmacology, vol. 589, no. 1-3, pp. 163-172, 2008.

[23] H. Dvir, H. L. Jiang, D. M. Wong et al., "X-ray structures of Torpedo californica acetylcholinesterase complexed with (+)huperzine A and (-)-huperzine B: structural evidence for an active site rearrangement," Biochemistry, vol. 41, no. 35, pp. 10810-10818, 2002.

[24] Y. Nicolet, O. Lockridge, P. Masson, J. C. FontecillaCamps, and F. Nachon, "Crystal structure of human butyrylcholinesterase and of its complexes with substrate and products," The Journal of Biological Chemistry, vol. 278, no. 42, pp. 41141-41147, 2003.

[25] J. Ma, M. Yoshimura, E. Yamashita, A. Nakagawa, A. Ito, and T. Tsukihara, "Structure of rat monoamine oxidase A and its specific recognitions for substrates and inhibitors," Journal of Molecular Biology, vol. 338, no. 1, pp. 103-114, 2004.

[26] C. Binda, P. Newton-Vinson, F. Hubálek, D. E. Edmondson, and A. Mattevi, "Structure of human monoamine oxidase B, a drug target for the treatment of neurological disorders," Nature Structural Biology, vol. 9, no. 1, pp. 22-26, 2001.

[27] A. N. Jain, "Surflex: fully automatic flexible molecular docking using a molecular similarity-based search engine," Journal of Medicinal Chemistry, vol. 46, no. 4, pp. 499-511, 2003.

[28] E. Kellenberger, J. Rodrigo, P. Muller, and D. Rognan, "Comparative evaluation of eight docking tools for docking and virtual screening accuracy," Proteins, vol. 57, no. 2, pp. 225242, 2004.

[29] P. A. Holt, J. B. Chaires, and J. O. Trent, "Molecular docking of intercalators and groove-binders to nucleic adds using autodock and surflex," Journal of Chemical Information and Modeling, vol. 48, no. 8, pp. 1602-1615, 2008.

[30] M. Yang, L. Zhou, Z. Zuo, X. Tang, J. Liu, and X. Ma, "Structure-based virtual screening for glycosyltransferase51," Molecular Simulation, vol. 34, no. 9, pp. 849-856, 2008. 


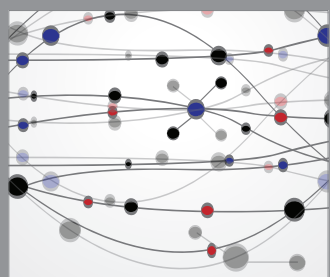

The Scientific World Journal
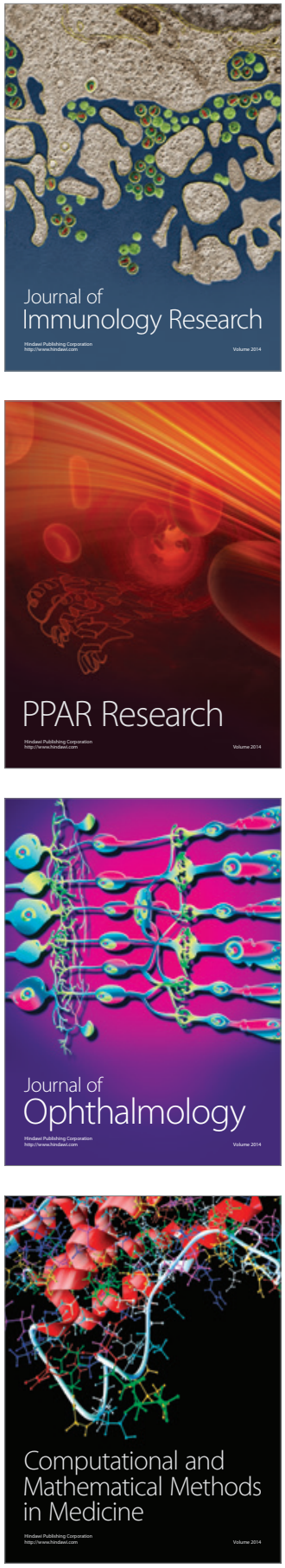

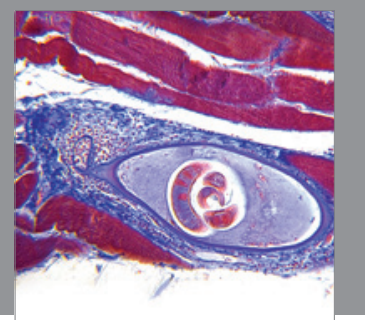

Gastroenterology

Research and Practice
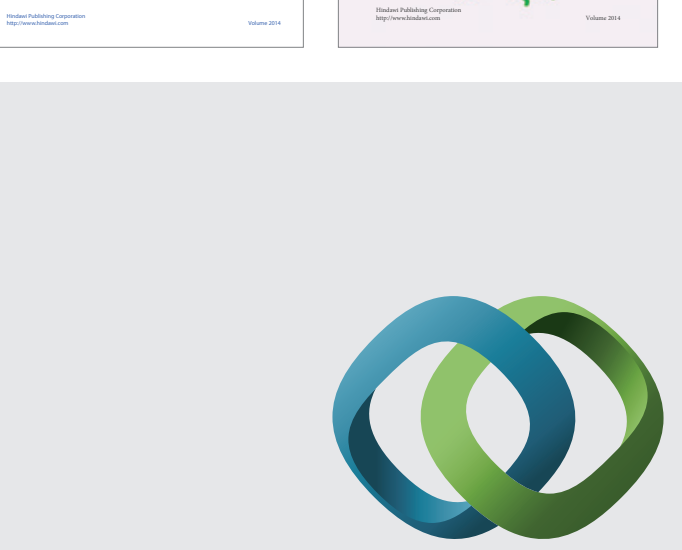

\section{Hindawi}

Submit your manuscripts at

http://www.hindawi.com
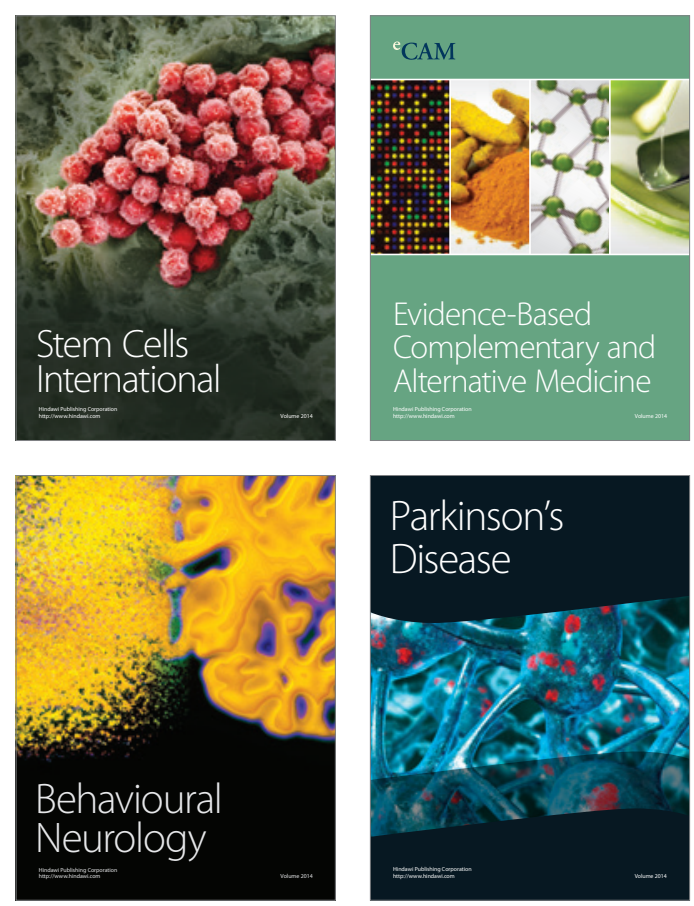

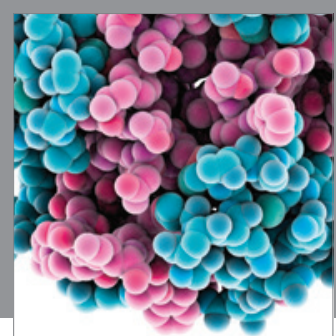

Journal of
Diabetes Research

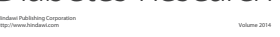

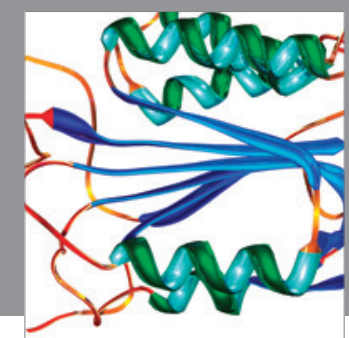

Disease Markers
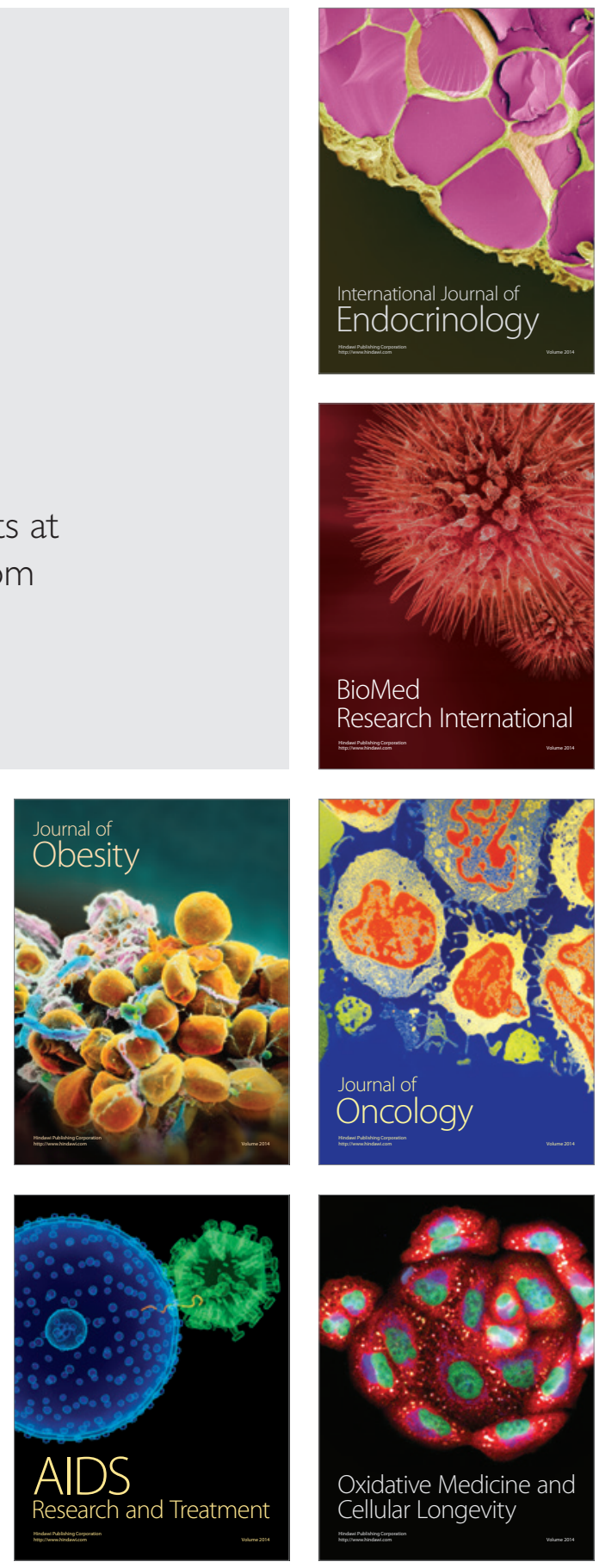